Check for updates

London, UK

Cite this as: BMJ 2020;370:m3269 http://dx.doi.org/10.1136/bmj.m3269 Published: 19 August 2020

\section{Covid-19: England to test 150000 people every two weeks to track local outbreaks}

\author{
Jacqui Wise
}

The Office for National Statistics (ONS) is to expand its infection survey to 150 ooo people a fortnight in England by October, up from the current 28 ooo, in order to provide more information about the spread of covid-19 infection within the community and help to identify local outbreaks. ${ }^{1}$

The aim is to eventually enrol 400000 people in England. The ONS has also partnered with Scotland, Wales, and Northern Ireland to extend the survey across the UK. The infection survey started as a pilot in May to track infection rates outside of hospitals and care homes, regardless of whether a person has symptoms.

Latest data from the survey shows an estimated 28300 people within the community population in England had covid-19 during the week of 3 to 9 August, equating to $0.05 \%$ of the population or around 1 in 1900 people. $^{2}$

The ONS says there is some evidence of a small increase in the percentage of people testing positive for covid-19 in July but this appears to now have levelled off. However, this estimate is based on just 58 people from 58 households testing positive out of 122021 swab tests collected over six weeks.

Katherine Kent, co-lead for the survey analysis at the ONS, told a Science Media Centre briefing on 19 August, "With a larger sample we can decrease the confidence intervals around our estimates and so can have more certainty. We can get weekly data on the spread of infection and provide granular estimates down to a local level.”

The Department of Health said the study will allow government and local authorities to further narrow down the areas which may be experiencing outbreaks, potentially reducing the number of people affected by new restrictions.

Health secretary Matt Hancock said, “This country now has the capacity to test for coronavirus on an unprecedented scale and this ONS survey will be a crucial part of this work -improving our understanding of the rate of infection in the population and how many people have antibodies. This will allow us to further narrow down the areas potentially affected by local outbreaks and continue our fight to curb the spread ahead of winter."

The ONS said they will prioritise ramping up testing in the north west of England and London in light of recent upticks in these areas. Kent said, "By increasing the sample size at local authority level we will be able to support decision making on appropriate interventions.”

Participants provide samples from self-administered nose and throat swabs every week for the first five weeks and then every month for 12 months. A fifth of participants also provide a blood sample taken by a trained nurse or phlebotomist in order to determine what proportion of the population has developed antibodies to covid-19.

Sarah Walker, professor of medical statistics and epidemiology at Oxford University and chief investigator of the survey, told the briefing that current infection levels are low. "The point of the scale up is that if we have a problem in October we will not be caught unawares at a national or a local level."

She added that because the survey followed the same people over time it could answer critically important questions such as whether people could get covid-19 more than once and whether antibodies provide protection.

The government has also announced a £2m ( $€ 2.2 \mathrm{~m}$; \$2.6m) grant to the ZOE covid-19 symptoms study app to support its data collection. ${ }^{3}$ Users of the app regularly report on their health and symptoms and whether they have tested positive for covid-19 with data analysed in collaboration with King's College London.

1 Office for National Statistics. Huge expansion of ONS led testing study will provide new insight into spread of covid-19 across the UK. 18 August 2020. www.ons.gov.uk/news/news/newinsightintocovid19tobegainedfromhugeboosttonationaltestingstudyledbytheofficefornationalstatistics.

2 Office for National Statistics. Coronavirus (covid-19) infection survey pilot: England and Wales. 14 August 2020. www.ons.gov.uk/peoplepopulationandcommunity/healthandsocialcare/conditionsanddiseases/bulletins/coronaviruscovid19infectionsurveypilot/latest.

3 Mayor S. Covid-19: Researchers launch app to track spread of symptoms in the UK. BMJ2020;368:m1263. doi: 10.1136/bmj.m1263 pmid: 322220898 